\title{
Meta-Analysis Reveals a Critical Period for Management of Powdery Mildew on Hop Cones
}

Mark E. Nelson, Washington State University, Irrigated Agriculture Research and Extension Center, Prosser, 99350; David H. Gent, United States Department of Agriculture-Agricultural Research Service, Forage Seed and Cereal Research Unit, and Department of Botany and Plant Pathology, Oregon State University, Corvallis 97331; and Gary G. Grove, Washington State University, Irrigated Agriculture Research and Extension Center, Prosser

\begin{abstract}
Nelson, M. E., Gent, D. H., and Grove, G. G. 2015. Meta-analysis reveals a critical period for management of powdery mildew on hop cones. Plant Dis. 99:632-640

Results of 28 field trials conducted over a 12-year period investigating management of hop powdery mildew caused by Podosphaera macularis were quantitatively summarized by meta-analysis to compare product efficacy and use patterns by mode of action as defined by Fungicide Resistance Action Committee (FRAC) groups. Availability of original observations enabled individual participant data meta-analysis. Differences in control of powdery mildew on leaves and cones were apparent among fungicide FRAC groups when individual products were evaluated over the course of a growing season. FRAC groups 13, 3, and U13 provided the most efficacious control of powdery mildew on leaves. Percent disease control on cones was influenced by midseason foliar disease and fungicide mode-of-action. FRAC 13 provided significantly better disease control on cones than all other groups except U13, 3, and premixes of 7 with 11. Disease control on leaves was similar when a rotational program of fungicides was used, independent of the

modes of action, but improved on cones if FRAC groups 13 and 3 were both included compared with programs consisting of FRAC groups 11 and 3,11 and 5, or 3 and 5. Disease control on cones was improved from 32 to $52 \%$, on average, when the fungicide quinoxyfen (FRAC 13) was applied at least once during the early stages of cone development, defined in this analysis as 20 July to 10 August, as compared with all other treatments. Efficacy of disease control on cones by quinoxyfen was moderated by and interacted with the incidence of leaves with powdery mildew. Disease control on cones was further improved if two applications of quinoxyfen were made during this period. Collectively, these findings suggest that disease control during juvenile stages of cone development largely influences the success of fungicide programs and point to the critical importance of focusing management efforts during this stage of development, independent of what actual management strategy is employed.
\end{abstract}

The vast majority of U.S. hop (Humulus lupulus L.) production is located in Washington, Oregon, and Idaho (2), accounting for about $31 \%$ of the world's hop hectarage and $39 \%$ of the world's hop supply in 2013 (10). Hop powdery mildew, which is caused by Podosphaera macularis (Wallr.) U. Braun \& S. Takam., has been prevalent in England for over three centuries. It spread to continental Europe by the late 1800s $(18,29)$, and New York by the early 1900s $(3,12)$. The disease was first observed in commercial hop yards in the Pacific Northwest in 1997 (23). Many of the predominant cultivars grown in the Pacific Northwest had been developed in the absence of the pathogen and proved to be extremely susceptible to the disease. The emergence of powdery mildew in the Pacific Northwest hop-growing region resulted in a crisis management issue due to a lack of effective products registered for disease management $(8,20)$.

To address this crisis Washington State University (WSU) personnel initiated trials to evaluate fungicidal products for efficacy and crop safety. At least 32 synthetic or organic products were evaluated over the course of a decade, contributing to the registration of at least nine synthetic fungicide chemistries in five chemical classes as defined by the Fungicide Resistance Action Committee (FRAC) (1). Treatments consisting of rotational programs were included in many of these trials to better define when and how to utilize many of these products and product combinations.

Results from these comprehensive and inclusive trials were reported to industry groups, funding agencies, and chemical companies while

Corresponding author: M. Nelson; E-mail: mark_nelson@wsu.edu

Accepted for publication 25 September 2014.

http://dx.doi.org/10.1094/PDIS-04-14-0396-RE

This article is in the public domain and not copyrightable. It may be freely reprinted with customary crediting of the source. The American Phytopathological Society, 2015. some were published in the journals Fungicide and Nematicide Tests, Biological and Cultural Tests for Control of Plant Diseases, and Plant Disease Management Reports. However, additional analysis of collated data can provide synthesis of results among chemical groups and, more importantly, analytical insights into the epidemiology of the disease. Meta-analysis has become a standardized and accepted statistical framework for synthesis of results across studies $(19,22,24,25)$. The availability of the original observations, referred to as "individual participant data" (IPD), from all these studies contributes an additional level of analysis not usually available for meta-analysis (4,19,35).

IPD meta-analyses can be conducted in a two-stage or one-stage process. In a two-stage process, each study is analyzed in a consistent manner, effect sizes are calculated, and then effect sizes are aggregated using standard meta-analysis approaches $(4,32)$. In a onestage approach, available individual participant data are analyzed in a single analysis, simultaneously calculating both within-study and between-study heterogeneity to estimate overall treatment effects (32).

There are many advantages to IPD meta-analysis over meta-analysis based on aggregate data obtained from literature. Access to raw data enables consistent data quality assurance, the ability to perform a wide variety of statistical analyses in every available study, and the ability to control for participant-level covariates $(4,28)$. The latter point is particularly important when different subpopulations are evaluated in different studies and relevant covariates vary among individuals. In a meta-analysis based on aggregated data, between-study interactions are based on aggregated participant characteristics (e.g., mean disease severity in a nontreated control), and have low power to detect interactions at the individual plant or plot level $(16,31)$. Such interactions may be important, such as when fungicide efficacy varies between affected tissues (for example, fruit and foliage). One-stage IPD meta-analysis methods may be most appropriate when trials are small, participant numbers are few, and heterogeneity across trials is substantial. In such instances, two-stage methods have less statistical power and may lead to erroneous conclusions due to differences in subpopulations evaluated 
among studies (34). Disadvantages of IPD meta-analysis may include the effort of collating raw data, bias due to limited availability of raw data (27), and increased computational complexity $(28,34)$.

Conclusions of meta-analysis to summarize the results of 28 trials conducted by WSU personnel over a 12-year period are reported here. The objectives of this analysis were to (i) quantify the efficacy of fungicides by FRAC groups (1), (ii) evaluate efficacy of various fungicide rotational programs, and (iii) identify periods or crop growth stages important in effective disease management.

\section{Materials and Methods}

Trial descriptions. Between 2001 and 2012, 28 trials were conducted in five different research hop yards located in south-central Washington State. In 2001, trials were conducted in three different yards: one located at a United States Department of Agriculture (USDA) research farm near Central Ferry, WA ('Galena') planted on a 1-by-3-m plant-by-row spacing under a 3-m trellis, and two located at the WSU-Prosser Irrigated Agriculture Research and Extension Center ('Galena' and 'Columbus', respectively) both planted on a 2.1-by-2.1-m plant-by-row spacing under a 5.4-m trellis. In 2002, trials were conducted at a USDA research farm located near Moxee, WA on an unnamed cultivar planted on a 2.1-by-4.2-m plant-by-row spacing under a 5.4-m trellis. In 2003, the Moxee trellis was modified to $2.7 \mathrm{~m}$ and the yard was replanted to 'Zeus' on a 2.1-by-4.2-m plant-by-row spacing, with additional trials conducted during 2004 to 2006. During 2007 to 2012, trials were conducted in another research yard located at WSU-Prosser (Galena) planted on a 1-by3.1-m plant-by-row spacing under a 3.1-m trellis. In both 2001 WSU-Prosser trials, irrigation was delivered as needed by rill, with all other trials irrigated by drip.

Treatments in all trials were arranged as randomized complete blocks with four replications. Depending on crop growth stage and trial objectives, spray treatments were applied with water at 390 to 1,620 liters/ha with either Stihl model BR400 or SR420 mist blowers (Stihl, Virginia Beach, VA), except in both 2001 WSU-Prosser trials, where treatments were applied with water at 655 to 1,310 liters/ha with a handgun powered by a Hypro high-pressure sprayer (Pentair, New Brighton, MN). Applications were usually initiated in mid- to late-May but occasionally in mid-June and continued until sometime between mid-July and early September at 6- to 21day intervals (most commonly 2 -week intervals), with between 4 and 14 applications, depending on specific treatment and trial objectives.

Data collection. In total, 50,477 leaves and 185,308 cones were evaluated from 273 treatments applied to 1,092 plots in the 28 trials included in this meta-analysis. These results are from 1,970 individual spray tanks each applied to four replicated plots, resulting in 7,880 individual plot applications. Midseason foliar evaluations utilized in this analysis were conducted between 25 June and 22 July, a period when the incidence of leaves with powdery mildew typically is the greatest. The mean number of leaves evaluated per replication was 53.0 (standard deviation =10.9). Evaluation of cone disease incidence was conducted 1 to 2 weeks after the final treatment application for any given trial. Disease evaluations were conducted by visual examination of arbitrarily selected leaves and cones for signs of powdery mildew. The mean number of cones evaluated per replication was 170.8 (standard deviation $=50.5$ ). Disease levels observed in the nontreated controls ranged between 8.5 and $96.1 \%$ on leaves and 3.2 and $100 \%$ on cones (Fig. 1).

The azanapthalene (FRAC 13) fungicide quinoxyfen (Quintec; Dow AgroSciences LLC, Indianapolis, IN) is highly active against powdery mildew diseases, and of particular interest in these analyses because of its efficacious control of powdery mildew in certain individual trials as well as its appearance in a large number of trials. A number of treatments within trials were specifically designed to utilize the apparent efficacy of quinoxyfen to identify crop growth stages important for disease management. Quinoxyfen was also included as a rotational product in treatments designed to identify when and if many other products might be incorporated into disease management programs. As a result, quinoxyfen was included in rotations with many products of varying efficacy in these trials, as described below.

Data analysis. A one-stage mixed-effects IPD meta-analysis was utilized to evaluate the effect of several dichotomous or categorical variables on mean disease control. The minimum requirements for a trial to be considered in the analysis were that the trial (i) possessed at least four replications, (ii) possessed a nontreated control where mean powdery mildew was present at some nonzero level, and (iii) included a measurement of the incidence of leaves with powdery mildew in late June to early July or an estimate of incidence of cones with powdery mildew at harvest. Products included in trials composing the meta-analysis are provided in Table 1. In total, 24 trials were available for disease incidence on leaves, 28 were available for cones, and 24 had both. For a specific treatment to be considered in the analyses, that treatment had to appear in at least three independent trials.

As a first analysis, fungicide treatments were grouped according to their mode of action based on FRAC codes. Preliminary analysis indicated that oils contributed disproportionately to results for control of cone infection compared with other members of the FRAC "not classified" (NC) group. Subsequent analyses separated oils from all other products in the FRAC NC group and results for oils are reported separately. Although FRAC group NC includes a diverse set of products, the remaining members were retained as a single group because no individual product occurred in at least three separate trials.

Rotational programs of various fungicides were evaluated. Categorical variables were created to evaluate fungicide programs that included at least two fungicides with different FRAC codes, with each fungicide applied at least once but at different times during a trial. Premixes of quinone outside inhibitor (QoI; FRAC 11) with succinate dehydrogenase inhibitor (FRAC 7) fungicides occurred in sufficient trials as season-long treatments to evaluate efficacy of this combination on leaves and cones; for the purpose of this analysis, they were treated similarly to products with a single mode of action. From among the treatments that consisted of rotational programs of fungicides, an analysis also was conducted to evaluate the association of disease control on leaves and cones related to the FRAC code of the first fungicide applied.

Preliminary results indicated that quinoxyfen might be especially efficacious when applied during the early stages of cone development. A categorical variable was created for whether quinoxyfen was applied at least once during 20 July to 10 August or not. This time period corresponds approximately to stages I to III of cone development (14), a period when powdery mildew can be particularly damaging to hop cones (7). To minimize potential confounding from plots that received quinoxyfen for the duration of the entire season grouped with treatments where quinoxyfen was utilized in a rotational program with other fungicides or biological control agents, an additional categorical variable was created that enabled evaluation of quinoxyfen only when this fungicide was applied in a rotational program with at least one other fungicide with a dissimilar FRAC code. Three categorical variables were then evaluated: (i) quinoxyfen applied at least once during 20 July to 10 August, (ii) quinoxyfen applied at some time during a trial but not during 20 July to 10 August, and (iii) other fungicide programs that did not include quinoxyfen at any time.

Finally, categorical variables were created to evaluate the specific timing of quinoxyfen applications before, during, and after the period of early cone development. For studies that included at least one application of quinoxyfen during 20 July to 10 August, four timings and use patterns of quinoxyfen were apparent among trials, depending on when quinoxyfen was applied and whether it was applied in a rotational or blocking program (i.e., two sequential applications). These groups were quinoxyfen applied in (i) a blocking program with the first application before 20 July, (ii) a blocking program with the second application after 10 August, (iii) a blocking program with both applications made during 20 July to 10 August, and (iv) a rotational 
program with only a single application of quinoxyfen during 20 July to 10 August (not applied as part of a blocking program).

The analyses described above were conducted for disease data collected both on leaves and cones. In the case of analyses on leaves, a given fungicide (or rotational program) was only considered in any analysis if applied at least 10 days prior to the disease assessment to avoid potential spurious treatment effects from applications made later in the season.

To conduct the meta-analysis, plot-level data from each study were collated with reference to trial, block (replication) within a trial, and the variables described above, with each categorical variable analyzed in a separate meta-analysis. For each experiment, relative disease control on leaves and cones was calculated as the response ratio $(R), y_{T} / y_{c}$, where $y_{T}$ is the incidence (proportion) of powdery mildew on leaves or cones in a treated plot and $y_{c}$ is the incidence of powdery mildew on the corresponding plant tissue in the nontreated control in the same block. It would be possible to calculate $y_{T}$ based on the mean incidence of powdery mildew among all nontreated control plots within a trial instead of based on plot-specific values. Calculation of $y_{T}$ at the trial level would lead to better precision in the estimate of disease but obscure potential block-level variations in disease due to gradients in microclimate, inoculum density, or other factors that are controlled for by blocking. In this analysis, we chose to use plot-level measurements of the nontreated control because block-level differences in powdery mildew were sometimes observed in experiments, particularly on leaves.

The natural $\log$ of the response ratio +1 was used as the response variable in the analysis (19). The value of 1 was added to avoid having an undefined variable when disease levels in a given plot were 0 , which happened in 20 instances for cones and 57 instances for leaves. Data were treated as missing for a given block within a trial when the incidence of leaves or cones with powdery mildew was 0 (five instances for leaves and three for cones). Response ratios were back transformed (approximately) after analysis to percent disease control through the equation $100[1-(\exp [R]-1)]$.
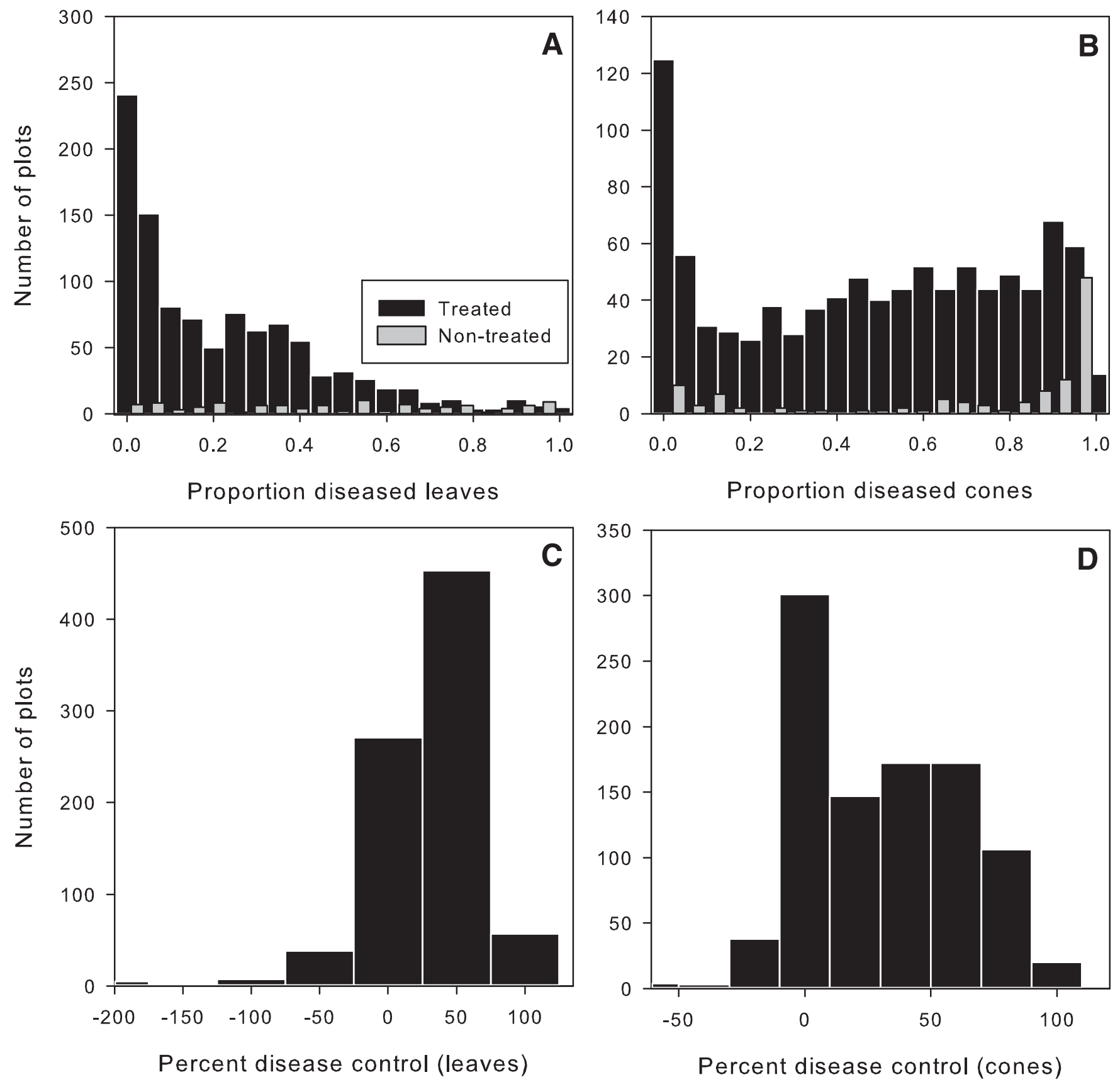

Fig. 1. Distribution of incidence of $\mathbf{A}$, leaves and $\mathbf{B}$, cones with powdery mildew among data sets used in meta-analysis. Percent disease control relative to nontreated control in a given experiment is given for $\mathbf{C}$ leaves and $\mathbf{D}$, cones. 
The general analysis approach was similar to methods used for analysis of multicenter evaluation of treatments (17). The general form of the model was $Y_{i j k}=\mu+\tau_{i}+t_{j}+(\tau t)_{i j}+b(t)_{j k}+e_{i j k}$, where $Y_{i j k}$ represents the dependent variable of $\ln (R+1)$ of treatment $i$ within block $k$ in trial $j, \mu$ represents the intercept, $\tau_{i}$ is the effect of treatment $i, t_{j}$ is the effect of trial $j,(\tau t)_{i j}$ is the interaction effect of treatment $i$ and trial $j, b(t)_{j k}$ is the effect of block $k$ in trial $j$, and $e_{i j k}$ is the error term. It is assumed that block, trial, and trial-treatment interactions are random and distributed $N\left(0, \sigma_{b}^{2}\right), N\left(0, \sigma_{t}^{2}\right)$, and $N\left(0, \sigma_{t t}^{2}\right)$, respectively. The errors also are random, independent, and distributed $e_{i j k}$ is approximately $N\left(0, \sigma^{2}\right)$.

Analysis of treatment effects on cones expanded the model given above to include a plot-level covariate for the incidence of leaves with powdery mildew. Again, we assumed that trial effects, replicate blocks within a trial, and trial-treatment effects were random. The model for this analysis was $Y_{i j k}=\mu+\tau_{i}+t_{j}+(\tau t)_{i j}+b(t)_{j k}+X(t)_{j k}+$ $\tau_{i} X(t)_{j k}+e_{i j k}$. The variables were as described above; $X(t)_{j k}$ is the effect of incidence of leaves with powdery mildew in block $k$ of study $j$, and $\tau_{i} X(t)_{j k}$ is the interaction of treatment $i$ and the incidence of leaves with powdery mildew in block $k$ of study $j$. The appropriateness of the covariate and its interaction with treatment were determined by its significance using a type $3 F$ test.

Analyses were carried out in the GLIMMIX procedure in SAS (version 9.3; SAS Institute, Cary, NC), with denominator degrees of freedom determined using a general Kenward-Roger approximation (15). The response distribution was specified as Gaussian and the "identity" link function was utilized in all analyses. Variance parameter estimates equal to 0 were removed from models and models were refitted. Least square means were compared by specific contrasts and the lsmeans options (pairwise least square mean difference) available in GLIMMIX. Least square means were calculated at the mean incidence of leaves with powdery mildew when this covariate was included in a model.

\section{Results}

FRAC group efficacy. The efficacy of disease control on leaves varied among FRAC groups $(P<0.002$; Table 2$)$. Percent foliar disease control was similar among quinoxyfen (FRAC 13), demethylation inhibitor (FRAC 3), and thiazolidine (FRAC U13) groups, ranging from 76 to $87 \%$. These fungicides provided significantly greater control of powdery mildew than the oil and not classified (FRAC NC) groups, with disease control of 33 and $30 \%$, respectively. Phenyl-acetemide (FRAC U6) was superior to FRAC NC. QoI (FRAC 11) and FRAC $11+7$ premixes had statistically similar disease control on leaves to all other groups (Fig. 2A).

Disease levels on cones were affected by midseason foliar disease $(P=0.002)$ and fungicide mode of action $(P=0.006$; Table 3$)$. FRAC 13 provided significantly better disease control on cones at $80 \%$ than all other groups except FRAC U13 (57\% disease control), FRAC 3 (44\% disease control), and the premix of FRAC $11+7$ (42\% disease control). The lowest level of disease control on cones was provided by the NC group (without oil), with $14 \%$ average reduction in disease. This was statistically similar to FRAC groups U6, oils, 11, and $11+7$ premix but less than the FRAC groups 3, U13, and 13 (Fig. 2B).

Table 1. Products, FRAC codes, and active ingredients tested in individual fungicide trials included in individual participant data meta-analysis

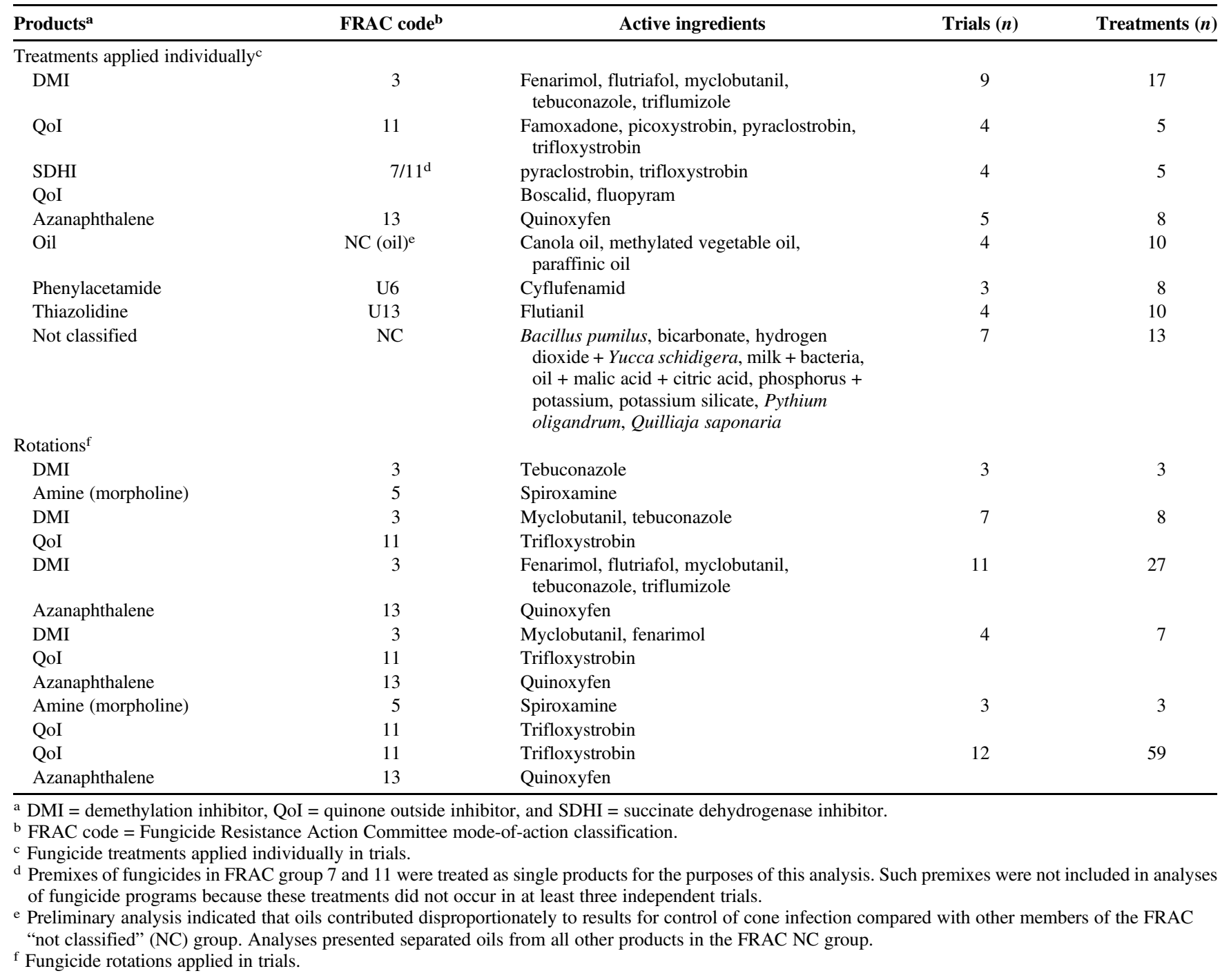


Effect of first fungicide application. When included in programs consisting of at least two FRAC groups, there was some evidence that disease control on leaves was superior when the premix of FRAC $11+7$ was used in the first treatment as compared with FRAC 13 or $11(P=0.015$; (Table 2; Fig. 3A). When evaluated as the first application of the season but as part of management programs, all FRAC groups provided similar control of powdery mildew on cones $(P=0.500)$ at harvest (Table 3; Fig. 3B).

Effect of fungicide programs involving multiple FRAC groups. Disease control on leaves was similar among the five fungicide programs $(P=0.669)$ utilizing at least two modes of action during the season (Fig. 4A), with control ranging between 52 and $61 \%$ (Table 2). However, there was an effect of fungicide program on disease control on cones $(P=0.028$; Table 3$)$. Because foliar disease levels were approximately similar, the incidence of leaves with powdery mildew did not influence percent disease control on cones $(P=$ $0.894)$ with these fungicide programs. Programs that included rotations of FRAC 13 and FRAC 3 tended to provide better disease control on cones than programs that utilized rotations of products in the FRAC 11 and FRAC 3, FRAC 11 and FRAC 5, or FRAC 3 and FRAC 5 groups. Fungicide programs that included FRAC 11 with another FRAC group provided disease control that was intermediate relative to the other programs evaluated (Fig. 4B).

Table 2. Summary statistics for type 3 test of fixed effects of fungicide mode of action and use patterns on the response ratio of hop powdery mildew on leaves ${ }^{\mathrm{a}}$

\begin{tabular}{lcccc}
\hline Factor or variable $^{\mathbf{b}}$ & Num DF & Den DF & $\boldsymbol{F}$ & $\boldsymbol{P}$ \\
\hline Fungicide mode of action & 7 & 17.69 & 5.24 & 0.002 \\
First spray & 6 & 38.6 & 3.06 & 0.015 \\
Fungicide program & 5 & 322.6 & 0.64 & 0.669 \\
\hline
\end{tabular}

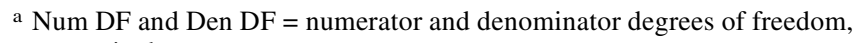
respectively.

${ }^{b}$ Fungicide mode of action is a comparison of Fungicide Resistance Action Committee (FRAC) codes for fungicides evaluated as a single product over the course of a season. First spray is a comparison of disease control related to the FRAC code of the first fungicide application in a program that consisted of at least two fungicides with differing FRAC codes. Fungicide program is a comparison of treatments that consisted of at least two fungicides with differing FRAC codes applied in a rotational or blocking program. See text for a detailed description of the treatments evaluated.
Essential disease management periods. The percent disease control on cones was improved 20\% (52 compared with $32 \%$ for all other treatments) if quinoxyfen (FRAC 13) was applied at least once between 20 July and 10 August compared with other fungicides applied during this time $(P=0.003$; Fig. 5A). Percent control of powdery mildew on cones by this timing of quinoxyfen was influenced by the incidence of leaves with powdery mildew $(P<0.0001)$ and an interaction of the incidence of leaves with powdery mildew and whether or not quinoxyfen was applied between 20 July and 10 August $(P=0.005$; Table 3$)$.

The effect of quinoxyfen on control of powdery mildew of cones was not due simply to artifacts in the analysis where this fungicide was applied as a single product for the duration of the season. Evaluation of quinoxyfen applied in programs indicated that the incidence of cones with powdery mildew was reduced $52 \%(P=0.008)$ when quinoxyfen was applied at least one time between 20 July and 10 August, compared with $33 \%$ with quinoxyfen applied at other times during the season but not during early cone development, and $34 \%$ when quinoxyfen was not applied at any time during the season (Fig. 5B). Again, in this analysis, percent disease control on cones was affected by the incidence of leaves with powdery mildew midseason $(P<0.0001)$ and the interaction of foliar disease intensity and quinoxyfen use $(P=0.002$; Table 3$)$.

Control of powdery mildew on cones was enhanced if two applications of quinoxyfen were made during early cone development. Such treatments resulted in a $65 \%$ disease reduction on cones $(P=$ 0.004; Fig. 5C). A single application of quinoxyfen during early cone development resulted in reductions in cone disease ranging from 44 to $48 \%$, independent of whether applied as part of a blocked treatment (i.e., two sequential applications) with the other sequential application either before or after this period, or as a single nonblocked application. In this analysis, effective disease management during early cone development apparently moderated the influence of midseason foliar disease on disease control on cones $(P=0.083$; Table 3$)$.

\section{Discussion}

This meta-analysis indicates that certain fungicides have varying efficacy for controlling hop powdery mildew on leaves versus cones, and points to the need to evaluate both tissues when conducting efficacy trials and other experiments. Certain fungicide mode of actions and management strategies can be more effectively targeted

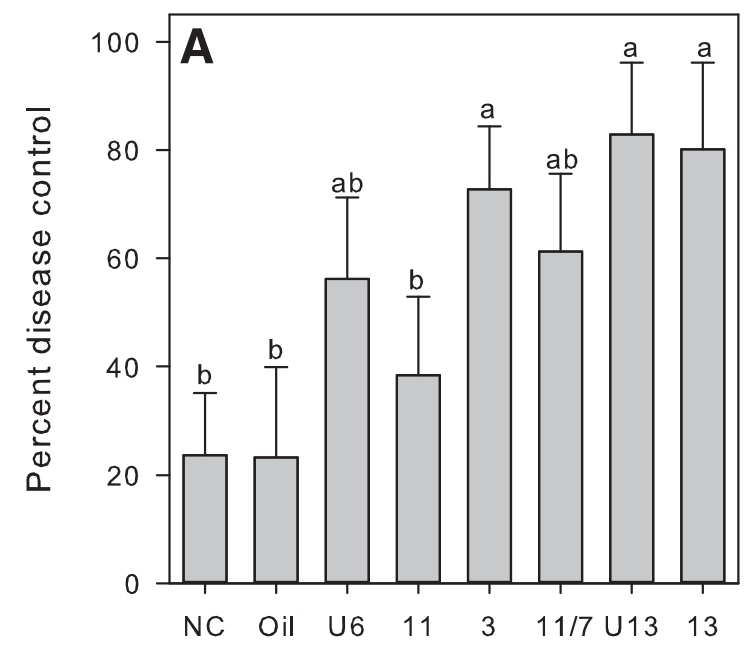

FRAC group

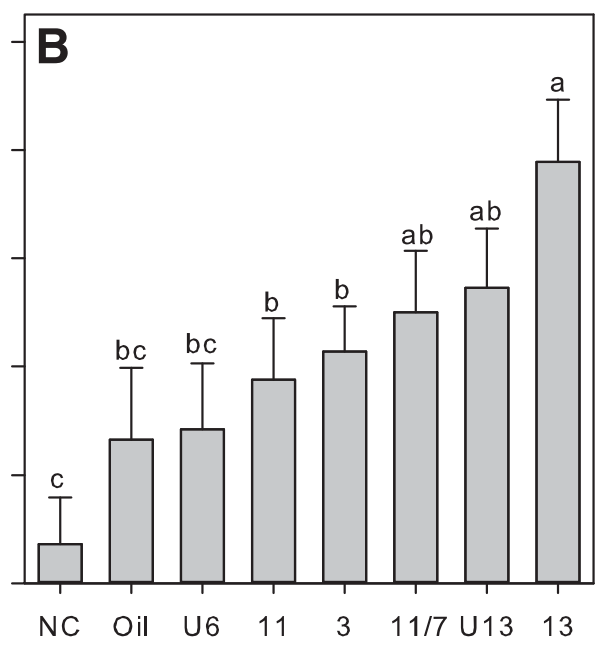

FRAC group

Fig. 2. Reduction of powdery mildew ( \pm confidence limits) on hop $\mathbf{A}$, leaves and $\mathbf{B}$, cones associated with fungicide mode of action as defined by the Fungicide Resistance Action Committee (FRAC) group. Disease control is expressed as percent reduction in relation to the nontreated control based on an individual participant data meta-analysis. Oils are separated from all other members of the "not classified" (NC) group because oil was included in sufficient trials to include separately and preliminary analysis indicated increased efficacy for suppressing cone infection compared with other members of that group. Products consisting of premixes of FRAC groups 11 and 7 are included in this analysis because they were applied as single-product tank preparations. Data are from 28 fungicide trials conducted during 2001 through 2012. Means followed by the same letter are not significantly different based on a mixed-effect individual participant data meta-analysis. The means for FRAC 11 versus 13 in A are also significantly different but could not be displayed with a letter designation. Means for FRAC 3 versus 13 are significantly different in $\mathrm{B}$. 
to specific plant growth stages to enhance disease control. Specifically, this meta-analysis revealed a period of cone development critical for effective management of hop powdery mildew.

In general, control of powdery mildew was greater on leaves than cones and efficacy of a fungicide for control of powdery mildew on leaves was not necessarily predictive of efficacy on cones. Of particular importance, the azanapthalene fungicide quinoxyfen (FRAC 13) provided an $80 \%$ reduction in disease incidence on cones. This was a $23 \%$ greater reduction in disease than the next most efficacious treatment (FRAC U13; pairwise contrast $P=0.0761$ ), and was significantly better than most other treatments. Although all fungicide programs provided comparable disease control on leaves, the inclusion of quinoxyfen in management programs tended to improve disease control on cones even when the specific application timing was not taken into account.

In Washington's Yakima Valley, early cone development generally occurs from late July through early August, depending on cultivar, when weather conditions tend to be hot and dry and considered unfavorable for development of hop powdery mildew $(20,26)$. However, the results presented here indicate that application of quinoxyfen during that period results in substantially better disease control than application of any other mode of action at that time. Disease control was further enhanced if two applications of quinoxyfen were made during this critical management period. More significantly, this provides

Table 3. Summary statistics for type 3 test of fixed effects of fungicide mode of action and use patterns on the response ratio of hop powdery mildew on cones ${ }^{\mathrm{a}}$

\begin{tabular}{|c|c|c|c|c|}
\hline Factor or variable ${ }^{b}$ & Num DF & Den DF & $\boldsymbol{F}$ & $\boldsymbol{P}$ \\
\hline Fungicide mode of action & 7 & 18.52 & 4.31 & 0.006 \\
\hline Disease incidence on leaves & 1 & 219 & 9.46 & 0.002 \\
\hline Interaction & $\ldots$ & $\ldots$ & $\ldots$ & $\ldots$ \\
\hline First spray & 6 & 35.43 & 0.91 & 0.500 \\
\hline Disease incidence on leaves & 1 & 502.7 & 0.83 & 0.361 \\
\hline Interaction & $\ldots$ & $\ldots$ & $\ldots$ & $\ldots$ \\
\hline Fungicide program & 5 & 8.607 & 4.43 & 0.028 \\
\hline Disease incidence on leaves & 1 & 398.9 & 0.02 & 0.894 \\
\hline Interaction & $\ldots$ & $\ldots$ & $\ldots$ & $\ldots$ \\
\hline Quinoxyfen application 20 July to 10 August & 1 & 33.66 & 9.33 & 0.003 \\
\hline Disease incidence on leaves & 1 & 821.6 & 45.98 & $<0.0001$ \\
\hline Interaction & 1 & 283.1 & 8.10 & 0.005 \\
\hline Seasonal quinoxyfen & 2 & 43.13 & 5.48 & 0.008 \\
\hline Disease incidence on leaves & 1 & 671.8 & 23.24 & $<0.0001$ \\
\hline Interaction & 2 & 276.8 & 6.31 & 0.002 \\
\hline Quinoxyfen use pattern 20 July to 10 August & 3 & 15.05 & 6.70 & 0.004 \\
\hline Disease incidence on leaves & 1 & 338.1 & 3.02 & 0.083 \\
\hline Interaction & $\ldots$ & $\ldots$ & $\ldots$ & $\ldots$ \\
\hline
\end{tabular}

a Num DF and Den DF = numerator and denominator degrees of freedom, respectively.

${ }^{b}$ Fungicide mode of action is a comparison of Fungicide Resistance Action Committee (FRAC) codes for fungicides evaluated as a single product over the course of a season. First spray is a comparison of disease control related to the FRAC code of the first fungicide application in a program that consisted of at least two fungicides with differing FRAC codes. Fungicide program is a comparison of treatments that consisted of at least two fungicides with differing FRAC codes applied in a rotational or blocking program. Quinoxyfen application 20 July to 10 August tested the effect of applying or not applying quinoxyfen at least once during 20 July to 10 August. Seasonal quinoxyfen is a comparison of use of quinoxyfen only when this fungicide was applied in a rotational program with at least one other fungicide with a dissimilar FRAC code at various times during the season. Quinoxyfen use pattern 20 July to 10 August is a comparison of quinoxyfen applications before, during, and after this time period. See text for a detailed description. Interaction terms were not included in models, and not presented if nonsignificant.
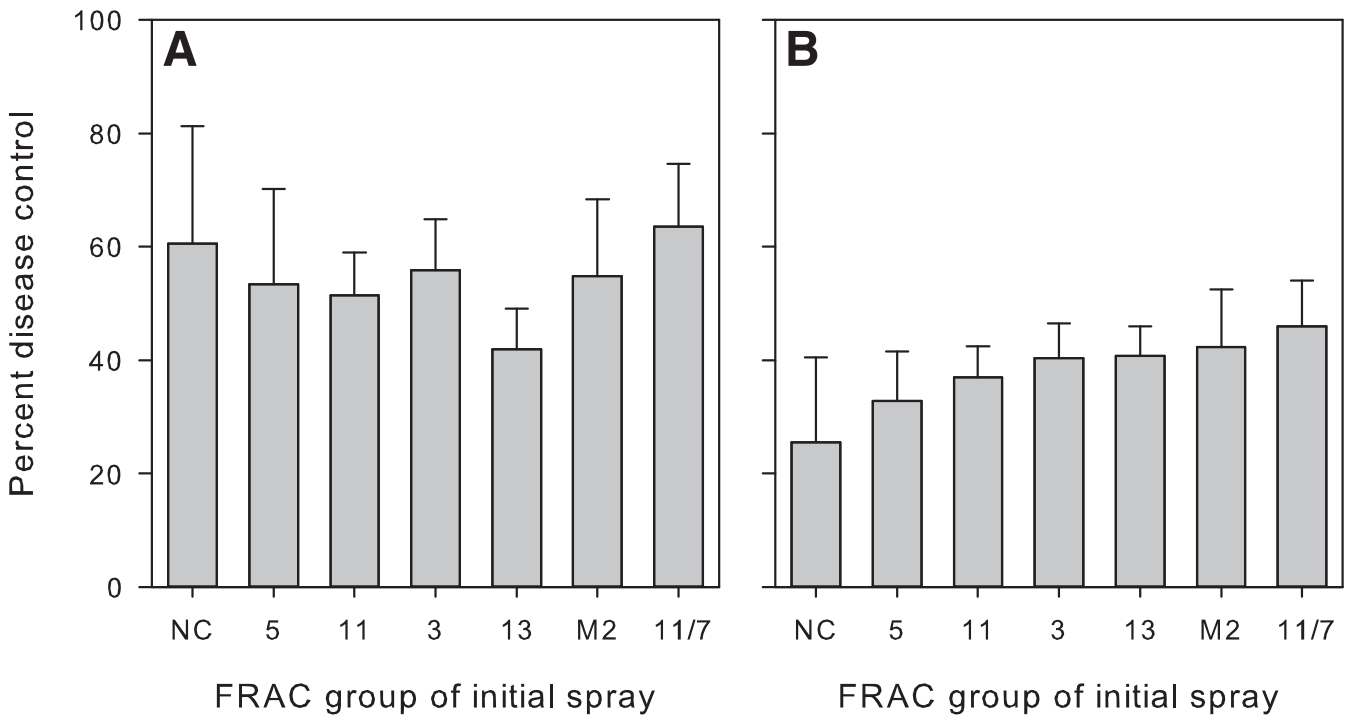

Fig. 3. Percent control of powdery mildew ( \pm confidence limits) on hop $\mathbf{A}$, leaves and $\mathbf{B}$, cones in relation to the mode of action of the initial fungicide application of the season. Fungicide mode of action as defined the Fungicide Resistance Action Committee (FRAC) group. Disease control is expressed as percent reduction in relation to the nontreated control in a given experiment. Means followed by the same letter are not significantly different based on a mixed-effect individual participant data meta-analysis. Means for FRAC 13 versus 11 and 13 versus 3 are significantly different in A but could not be displayed with a letter designation. 
evidence for a critical period for disease control and suggests that management efforts should especially be focused during early cone development.

It has long been believed that crop damage from powdery mildew primarily is due to disease on cones $(8,13,29)$, with the most severe epidemics assumed to be associated with disease during bloom and early cone development (29). The evidence of a critical period for management of powdery mildew on cones reported here is also supported by recent research that demonstrated that fungicide applications made during the early stages of hop cone development are essential for minimizing damage from powdery mildew to yield and cone quality factors (7). In recent studies involving highly susceptible cultivars, yield of $\alpha$-acids (the primary bitter acids important in brewing) was increased $20 \%$ by controlling powdery mildew through late July (stage II of cone development) compared with ceasing fungicide applications at bloom. However, additional fungicide applications after early cone development provided only modest improvements in yield of $\alpha$-acids (7).

Evidence for a critical management period for powdery mildew also is consistent with studies that have indicated that hop cones become progressively less susceptible to powdery mildew with advancing maturity $(30,38,39)$. The development of ontogenic resistance to powdery mildew in hop leaves has been described $(29,36)$, although its development on cones is less well characterized.

Similar critical periods of juvenile susceptibility to powdery mildew diseases have been reported on fruit of other crops, including $P$. pannosa on apricot and peach $(37,40)$ and $P$. aphanis on strawberry (5). The most critical period for managing powdery mildew fruit infection on grape (caused by Erysiphe necator) is prebloom through 3 weeks post fruit set $(6,33)$ and, for apple powdery mildew (caused by $P$. leucotricha), from 3 weeks before bloom to 3 weeks postbloom (21). It is believed that initiation of powdery mildew fruit infection on sweet cherry (caused by $P$. clandestina) also occurs on immature fruit (11).

In this study, an IPD meta-analysis approach was particularly useful to quantify the influence of disease intensity on leaves on the efficacy of certain fungicide treatments on disease control on cones. The impact of midseason foliar disease levels and interactions of those foliar disease levels with quinoxyfen efficacy when applied during early cone development supports previous reports that seasonlong disease management is essential to reduce inoculum pressure and maintain acceptable disease levels at harvest $(9,36)$. Based on the present results, even if relatively effective control strategies are applied to cones, high inoculum pressure (resulting from high disease levels on leaves) may still lead to unacceptable levels of disease on cones.
Because it is believed that effective early-season management practices are critical for successful disease suppression, the importance of mode of action included as the initial spray application was evaluated. Although quinoxyfen provided superior disease control on both leaves and cones when evaluated individually, this fungicide appeared to be among the least effective for reducing leaf infection at the midseason foliar evaluation when applied as the initial spray in a rotational program. However, this is likely an artifact of the efficacy of other fungicides utilized in rotational programs with quinoxyfen. Quinoxyfen was widely used in rotational programs with other modes of action, including those demonstrating relatively poor efficacy in all other evaluations obtained from the meta-analysis presented here (e.g., FRAC groups NC and 11). If a product from a given FRAC group was applied as the initial spray or as the initial block of two sprays, then something else, most commonly quinoxyfen, would come next. Similarly, many programs including these lesseffective fungicides were initiated with quinoxyfen. These factors likely account for these results. Furthermore, the FRAC group included in the initial application resulted in no differences in cone infection. These results suggest that mode of action of the initial spray application of the season may be no more important and possibly less important than later applications. Further research is required to fully test this hypothesis.

The results reported here indicate that disease management programs can likely be developed to both be consistent with FRAC resistance management guidelines and improve overall disease management by timing certain modes of action at appropriate crop growth stages. As new synthetic fungicides and biological control products are developed, testing should be designed to determine where these products might best fit into an overall disease management program, including determination of efficacy during both the foliar and early cone growth stages. The current study evaluated fungicides within a FRAC group as a single group although, given sufficient data, that approach is not necessary. For instance, the separation of oils from the remainder of the FRAC NC group suggests some potential differences in efficacy among active ingredients with the group. Although results may not be statistically significant, separating oils from other FRAC NC members may indicate trends and provide insights for future research. The trends seen here suggest that oils might be considerably more effective in reducing disease on cones than on leaves. Other FRAC NC members may be more effective in just the opposite manner; that is, reducing disease on leaves more effectively than on cones.

Beyond simple efficacy of fungicides, another insight from this meta-analysis is that fungicides themselves can be considered tools
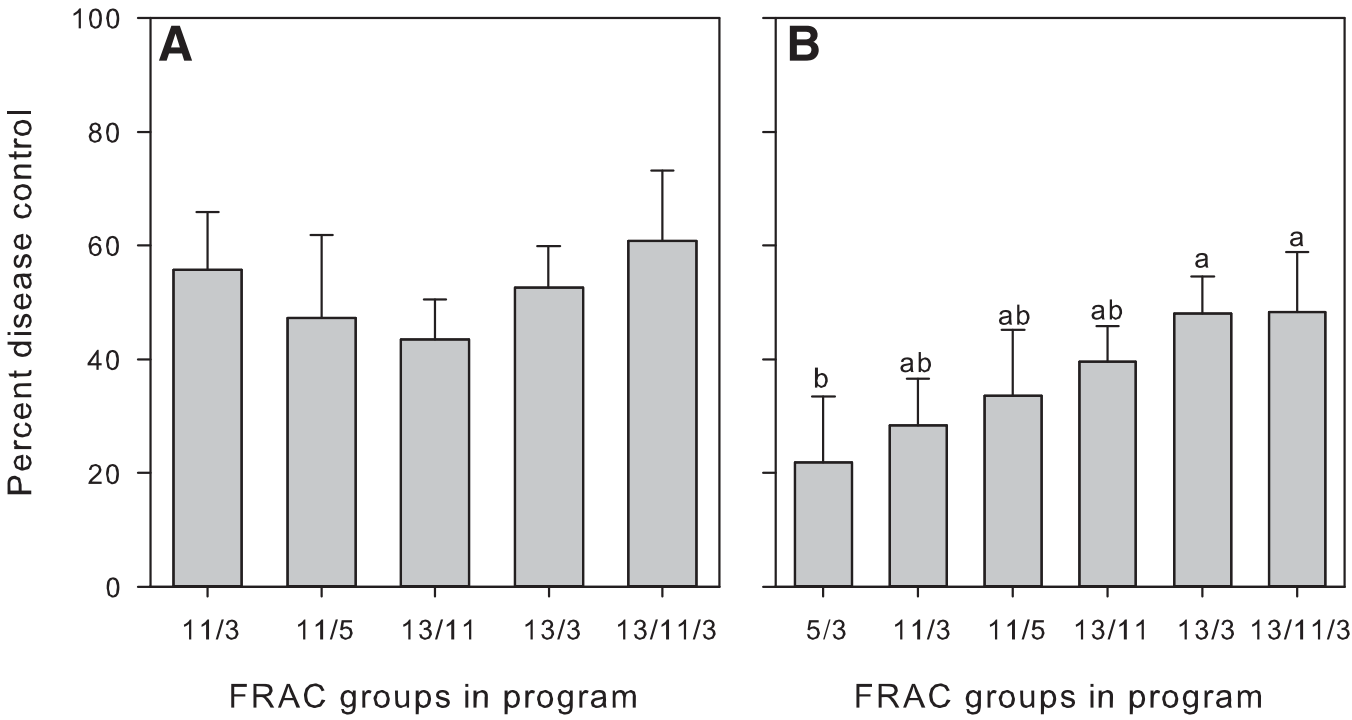

Fig. 4. Reduction of powdery mildew ( \pm confidence limits) on hop $\mathbf{A}$, leaves and $\mathbf{B}$, cones with fungicide programs consisting of at least two fungicide modes of action as defined by the Fungicide Resistance Action Committee (FRAC) group. Disease control is expressed as percent reduction in relation to the nontreated control in a given experiment. Means followed by the same letter are not significantly different based on a mixed-effect individual participant data meta-analysis. 

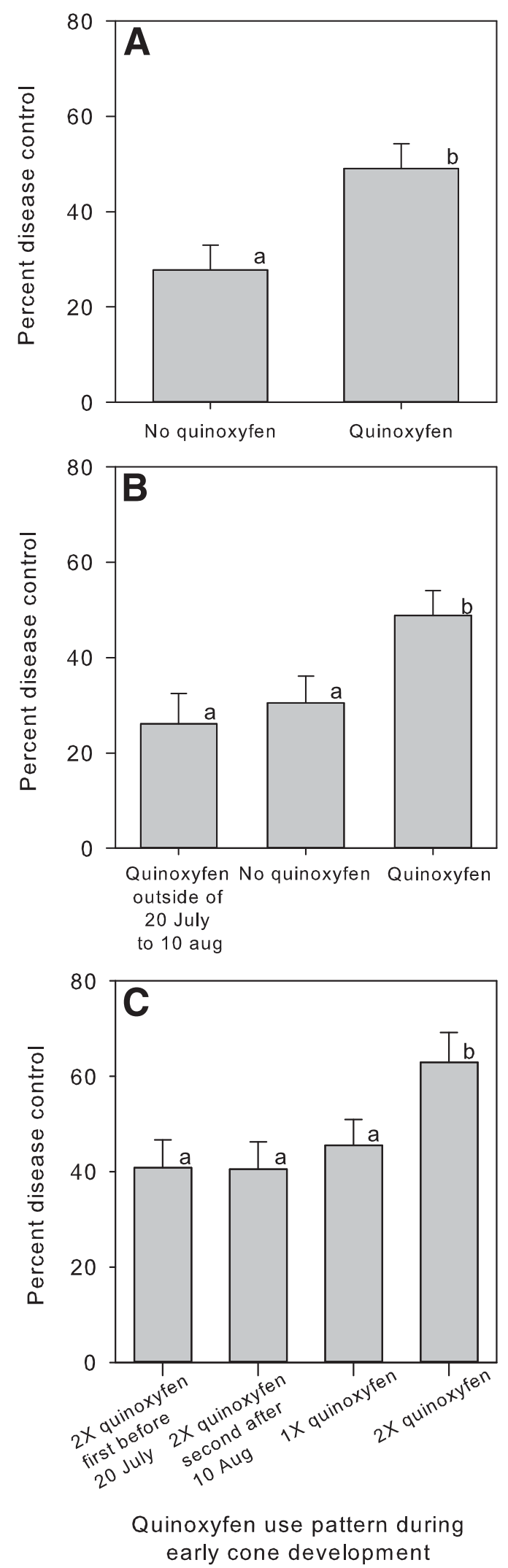

Fig. 5. Percent reduction in the incidence of powdery mildew ( \pm confidence limits) on hop cones in relation to timing of the fungicide quinoxyfen Fungicide Resistance Action Committee (FRAC) group 13. A, Disease control based on whether quinoxyfen was applied during the early stages of cone development (20 July to 10 August). B, Disease control when quinoxyfen was applied in a rotational program with at least one other fungicide in a different FRAC group during early cone development, at other times of the season, or when not applied at all. C, Disease control when quinoxyfen was applied in a blocking program (two sequential applications) near or during 20 July to 10 August, or as a single application. Means followed by the same letter are not significantly different based on a mixed-effects meta-analysis. to reveal crop growth stages or other events that are important for disease management but are difficult to identify in a single field study. Although quinoxyfen was known to be an efficacious fungicide for powdery mildew, synthesis of numerous trials involving this compound revealed an important period for disease management during early cone development, and provides guidance for additional research into the foliar phase of the disease. The identification of a critical management period on cones has broad implications for disease management regardless of what actual management strategy is employed. For example, this critical disease management period is important in organic management programs as well as those that include synthetic fungicides. The approach utilized in this study of exploiting differing fungicide efficacy combined with IPD meta-analysis to synthesize results from multiple trials could be a valuable tool for studying epidemics of other powdery mildews and diseases.

\section{Acknowledgments}

Financial support for this research was provided by Washington State University Agriculture Research Center (ARC), Hop Research Council, Washington Hop Commission, Washington State Commission on Pesticide Registration, numerous fungicide manufacturers, USDA-ARS CRIS 5358-21000-040-00, and USDA Specialty Crops Research Initiative. We thank P. Ojiambo, W. Mahaffee, and L. Madden for review of an earlier draft of the article; L. Madden for his guidance on statistical analyses; the senior editor and two anonymous reviewers for helpful suggestions that improved this article; and our technical and field support staffs for their work over the past decade that made this research possible.

\section{Literature Cited}

1. Anonymous. 2013. FRAC Code List 2013: Fungicides sorted by mode of action (including FRAC Code numbering). Fungicide Resistance Action Committee, Basel, Switzerland.

2. Anonymous. 2013. National Hop Report. National Agricultural Statistics Service, United States Department of Agriculture. December, 2013.

3. Blodget, F. M. 1913. Hop mildew. Bull. Cornell Univ. Agric. Exp. Stn. 328: 278-310.

4. Borenstein, M., Hedges, L. V., Higgins, J. P. T., and Rothstein, H. R. 2009. Introduction to Meta-Analysis. John Wiley \& Sons, Chichester, UK

5. Carisse, O., and Bouchard, J. 2010. Age-related susceptibility of strawberry leaves and berries to infection by Podosphaera aphanis. Crop Prot. 29: 969-978.

6. Gadoury, D. M., Seem, R. C., Ficke, A., and Wilcox, W. F. 2003. Ontogenetic resistance to powdery mildew in grape berries. Phytopathology 93:547-555.

7. Gent, D. H., Grove, G. G., Nelson, M. E., Wolfenbarger, S. N., and Woods, J. L. 2013. Crop damage caused by powdery mildew on hop and its relationship to late season management. Plant Pathol. 63:625-639.

8. Gent, D. H., Nelson, M. E., George, A. E., Grove, G. G., Mahaffee, W. F. Ocamb, C. M., Barbour, J. D., Peetz, A., and Turechek, W. W. 2008. A decade of hop powdery mildew in the Pacific Northwest. Online publication. Plant Health Prog.

9. Gent, D. H., Nelson, M. E., Grove, G. G., Mahaffee, W. F., Turechek, W. W., and Woods, J. L. 2012. Association of spring pruning practices with severity of powdery mildew and downy mildew on hop. Plant Dis. 96:1343-1351.

10. George, A. 2014. 2013 HGA Statistical Report. Hop Growers of America, Moxee, WA.

11. Grove, G. G., and Boal, R. J. 1991. Factors affecting germination of conidia of Podosphaera clandestina on leaves and fruit of sweet cherry. Phytopathology 81:1513-1518.

12. Hoerner, G. R. 1949. Hop diseases in the United States. Brew. Dig. 24:45-51.

13. Hysert, D., Probasco, G., Forster, A., and Schmidt, R.1998. Effect of hop powdery mildew on the quality of hops, hop products, and beer. In: Proc. Annu. Meet. Am. Soc. Brew. Chem. 1998. American Society of Brewing Chemists, Boston

14. Kavalier, A. R., Litt, A., Ma, C., Pitra, N. J., Coles, M. C., Kennelly, E. J., and Matthews, P. D. 2011. Phytochemical and morphological characterization of hop (Humulus lupulus L.) cones over five developmental stages using high performance liquid chromatography coupled to time-of-flight mass spectrometry, ultrahigh performance liquid chromatography photodiode array detection, and light microscopy techniques. J. Agric. Food Chem. 59:4783-4793.

15. Kenward, M. G., and Rogers, J. H. 1997. Small sample inference for fixed effects from restricted maximum likelihood. Biometrics 53:983-997.

16. Lambert, P. C., Sutton, A. J., Abrams, K. R., and Jones, D. R. 2002. A comparison of summary participant level covariates in metaregression with individual participant data meta-analysis. J. Clin. Epidemiol. 55:86-94.

17. Littell, R. C., Milliken, G. A., Stroup, W. W., Wolfinger, R. D., and Schabenberger, O. 2006. SAS for Mixed Models. SAS Institute, Cary, NC.

18. Liyanage, A., De, S., and Royle, D. J. 1976. Overwintering of Sphaerotheca humuli, the cause of hop powdery mildew. Ann. Appl. Biol. 83:381-394. 
19. Madden, L. V., and Paul, P. A. 2011. Meta-analysis for evidence synthesis in plant pathology: An overview. Phytopathology 101:16-30.

20. Mahaffee, W. F., Thomas, C. S., Turechek, W. W., Ocamb, C. M., Nelson, M. E., Fox, A., and Gubler, W. D. 2003. Responding to an introduced pathogen: Podosphaera macularis (hop powdery mildew) in the Pacific Northwest. Online publication. Plant Health Prog.

21. Marine, S. C., Yoder, K. S., and Baudoin, A. 2010. Powdery mildew of apple. Online publication. Plant Health Instruct.

22. Ngugi, H. K., Esker, P. D., and Scherm, H. 2011. Meta-analysis to determine the effects of plant disease management measures: Review and case studies on soybean and apple. Phytopathology 101:31-41.

23. Ocamb, C., Klein, R., Barbour, J., Griesbach, J., and Mahaffee, W. 1999. First report of hop powdery mildew in the Pacific Northwest. Plant Dis. 83:1072.

24. Ojiambo, P. S., Paul, P. A., and Holmes, G. J. 2010. A quantitative review of fungicide efficacy for managing downy mildew in cucurbits. Phytopathology 100:1066-1076.

25. Ojiambo, P. S., and Scherm, H. 2006. Biological and application-oriented factors influencing plant disease suppression by biological control: A metaanalytical review. Phytopathology 96:1168-1174.

26. Peetz, A. B., Mahaffee, W. F., and Gent, D. H. 2009. Effect of temperature on sporulation and infectivity of Podosphaera macularis on Humulus lupulus. Plant Dis. 93:281-286.

27. Riley, R. D. 2010. Like it and lump it? Meta-analysis using individual participant data. Int. J. Epidemiol. 39:1359-361.

28. Riley, R. D., Lambert, P. C., and Abo-Zaid, G. 2010. Meta-analysis of individual participant data: rationale, conduct, and reporting. Br. Med. J. (Clin. Res. Ed.) 340:c221.

29. Royle, D. J. 1978. Powdery mildew of the hop. Pages 381-409 in: The Powdery Mildews. D. M. Spencer, ed. Academic Press, New York

30. Seigner, E., Seefelder, S., Haugg, B., Engelhard, B., Hasyn, S., and Felsenstein, F. G. 2003. Potential of powdery mildew (Sphaerotheca humuli) to infect hops
(Humulus lupulus) in various developmental stages. Gesunde Pflanzen 55: 29-33.

31. Simmonds, M. C., and Higgins, J. P. 2007. Covariate heterogeneity in metaanalysis: criteria for deciding between meta-regression and individual participant data. Stat. Med. 26:2982-2999.

32. Simmonds, M. C., Higgins, J. P. T., Stewart, L. A., Tierney, J. F., Clarke, M. J., and Thompson, S. G. 2005. Meta-analysis of individual patient data from randomized trials: a review of methods used in practice. Clin. Trials 2 209-217.

33. Stark-Urnau, M., and Kast, W. K. 1999. Development of ontogenetic resistance of powdery mildew in fruit of differently susceptible grapevines (cvs. Trollinger and Lemberger). Mitt. Klosterneuburg 49:186-189.

34. Stewart, G. B., Altman, D. G., Askie, L. M., Duley, L., Simmonds, M. C., and Stewart, L. A. 2012. Statistical analysis of individual participant data metaanalyses: a comparison of methods and recommendations for practice. PLoS One $7:$ e46042.

35. Sutton, A. J., and Higgins, J. P. T. 2008. Recent developments in metaanalysis. Stat. Med. 27:625-650.

36. Turechek, W. W., Mahaffee, W. F., and Ocamb, C. M. 2001. Development of management strategies for hop powdery mildew in the Pacific Northwest. Online publication. Plant Health Prog.

37. Weinhold, A. R. 1961. The orchard development of peach powdery mildew. Phytopathology 51:478-481.

38. Wolfenbarger, S. N., Nelson, M. E., Grove, G. G., Woods, J. L., and Gent, D. H. 2012. Characterization of ontogenic resistance to powdery mildew in hop cones. (Abstr.) Phytopathology 102:S4.137.

39. Woods, J. L., Nelson, M. E., Grove, G. G., and Gent, D. H. 2010. Ontogenic resistance to powdery mildew in hop cones: implications for disease management (Abstr.) Phytopathology 100:S138.

40. Yarwood, C. E. 1952. Apricot powdery mildew from rose and peach. Bull. Calif. Dep. Agric. 41:19-25. 